\title{
Güneş enerjisi santral (GES) yapım yerlerinin CBS dayalı çok kriterli karar analizi ile belirlenmesi: Karabük örneği
}

\author{
Deniz Arca *1®, Hülya Keskin Çıtıroğlu $2 \bowtie$ \\ 1Dokuz Eylül Üniversitesi İzmir MYO, Izmir, Türkiye \\ ${ }^{2}$ Yatırım İzleme ve Koordinasyon Başkanlığı, YİKOB, Aydın, Türkiye
}

\author{
Anahtar Kelimeler \\ Güneș enerjisi \\ Coğrafi bilgi sistemleri \\ Çok kriterli karar analizi \\ Karabük
}

\begin{abstract}
ÖZ
Günümüzün globalleșen dünyasında insanoğlunun temel ihtiyaçlarından biri olan enerji, teknolojinin ilerlemesi ile daha da önem kazanmıștır. Geleneksel yöntemler ile enerji üretimindeki sınırlamalar ve çevresel kaygılar neticesinde, yenilenebilir enerjiye doğru hızlı bir yönelim gerçekleşmektedir. Yenilenebilir enerji santrallerinin kurulumu ve işletme esnasındaki verimliliği açısından, yerlerinin seçimi büyük önem taşımaktadır. Güneş enerjisi, günümüzde hayatımızın önemli ve kaçınılmaz bir parçası haline gelmiş olan sürdürülebilir ve yenilenebilir enerji kaynakları arasında yer almaktadır. Güneş enerji santrallerin (GES) kurulum yerlerinin belirlenmesinde ekonomik, çevresel ve sosyal faktörlerin dikkate alınması oldukça büyük önem arz etmektedir. Bu çalışmanın amacı Karabük ilinde GES kurulabilecek en uygun alanların Coğrafi Bilgi Sistemleri (CBS) ve Çok Kriterli Karar Verme (ÇKKA) yöntemlerinden biri olan Analitik Hiyerarşi Yöntemi (AHY) kullanılarak belirlenmesidir. Elde edilen sonuçlara göre, çalışma alanının GES yapımı için orta ve düşük duyarlılık düzeyinde olduğu tespit edilmiştir.
\end{abstract}

\section{GIS-Based analysis of sites determination for solar power plant (SPP) by multi-criteria decision analysis method: A case study in Karabük}

\section{Keywords}

Solar power

Geographical information

systems

Multi-criteria decision analysis

method

Karabük

\begin{abstract}
Energy, which is one of the basic needs of human beings in today's globalizing world, has gained more importance with the advancement of technology. As a result of the limitations in energy production with traditional methods and environmental concerns, a rapid shift towards renewable energy is taking place. The selection of their location is of great importance in terms of the establishment of renewable energy plants and their efficiency during operation. Solar energy is among the sustainable and renewable energy sources that have become an important and inevitable part of our lives today. It is very important to take into account the economic, environmental and social factors in determining the installation locations of solar power plants (SPPs). The aim of this study is to determine the most suitable areas for SPP in Karabük using Geographic Information Systems (GIS) and Analytical Hierarchy Process (AHP), one of the Multi Criteria Decision analysis (MCDA) methods. According to the results, it has been determined that the study area is at medium and low sensitivity level for SPP construction.
\end{abstract}




\section{GíRIş}

Teknolojinin ve sanayileşmenin hızlı gelişimi, dünyadaki zaten sınırlı ve gelecekte tükenecek olan yeraltı fosil kaynaklarının da hızla tüketilmesine sebep olmaktadır. Özellikle çağımızda kentlerdeki yaşam kalitesin de artmasıyla elektrik enerjisine olan talep daha da artmaktadır. Artan bu enerji türünün karşılanmasında ve üretilmesinde, tükenmeye başlayan fosil yakıtlar artık yerini alternatif ekonomik, yenilenebilir ve çevre dostu enerji kaynaklarına bırakmaktadır (Can ve Erbıyık, 2020). Bu nedenle sürdürülebilir elektrik enerjisi üretiminde fosil yakıtlar yerine alternatif ve yenilenebilir enerji kaynaklarının kullanılması önem sunmaktadır (Can, 2019). Dünya elektrik üretimi göz önüne alındığında yenilenebilir enerji kaynaklarının önemli bir yere sahip olduğu görülmektedir. Toplam küresel elektrik üretiminin \%26,2'si yenilenebilir kaynaklardan elde edilirken bu oranının sadece \%2,4'ü güneş santrallerinden sağlanmaktadır (REN21, 2019). Türkiye'de de elektrik üretiminde kömür ve doğal gaz kaynaklarının üstünlüğü bulunmaktadır. Toplam elektrik üretiminin \%32,08'i yenilenebilir kaynaklardan elde edilirken güneş enerjisinin bu üretim içindeki payı \%2,56'dır. Türkiye'nin yenilenebilir enerji kaynaklarından elektrik enerjisi üretiminin dağılımı incelendiğinde de güneş enerjisinin \%7,98'lik bir paya sahip olduğu görülmektedir (TEİAŞ, 2020). Yenilenebilir enerji kaynaklarından biri olan güneş enerjisi, tükenmeyen ve temiz bir enerji kaynağıdır. Karbon monoksit (CO), kükürt (S), duman, gaz, radyasyon, koku ve ses gibi çevreyi kirletici unsurları barındırmamaktadır (Çağlayan ve ark., 2014). Güneş enerjisinin kullanım alanları; elektrik üretimi, ısıtma, soğutma, kurutma, aydınlatma, hesap makineleri, saatler ve trafik işaret lambalarının enerji temini, sıcak su eldesi, suyun damıtılması, mobil telefonların bataryalarının ve diğer taşınabilir cihazların şarj edilmesi, yemek pişirme, yapay uydu ve güneş kuleleri, güneş arabaları ve uçaklar olarak özetlenebilir (Alternatürk, 2020).

Hang ve ark. (2008) Çin'de sürdürülebilir bir gelecek için güneş enerjisi üzerine yaptıkları araştırmada Çin'de elektrik talebinin hızla arttığı üzerinde durmuşlar ve Çin'in batı ve kuzey bölgelerinde güneș kaynakları ve geniş araziler yaygın olarak mevcut olduğunu ortaya koymuşlardır. Sánchez-Lozano ve ark. (2013) Güney doğu İspanya'da yer alan Cartegena șehrinde Coğrafi Bilgi Sistemleri (CBS) ve Çok Kriterli Karar Analizi (ÇKKA) yöntemleri ile güneş çiftlikleri kurulabilecek alanları araştırmışlardır. Uyan (2013) Konya'nın Karapınar Bölgesinde (Türkiye) Analitik Hiyerarşi Yöntemi (AHY) kullanarak güneş çiftlikleri kurulabilecek alanları araştırmıştır. Effat (2013) Mısır'ın İsmailia İlinde mekik radar topoğrafya görevi ve çok kriterli karar analizi Yöntemi kullanarak güneş çiftlikleri kurulabilecek potansiyel alanların belirlenmesi üzerine çalıșmıștır. Suh ve Brownson (2016) CBS, Bulanık küme (Fuzzy sets) ve AHY kullanarak Kore'nin Ulleung Adasının güneş çiftlikleri için uygunluğunu araştırmışlardır. Uyan (2017) Konya İli (Türkiye) Çumra İlçesinde CBS ve AHY kullanarak güneş enerji santrali kurulabilecek alanların haritalanması üzerine yaptığı çalışma sonucu elde ettiği duyarlılık haritasını düşük, orta ve yüksek duyarlılı olarak üç kategoriye ayırmıștır. Yalçın ve Yüce (2020) CBS ve AHY kullanarak Burdur'da (Türkiye) güneş enerji santrali (GES) yatırımına uygun alanların belirlenmesi üzerine yaptıkları çalışma sonucunda Burdur merkez, Gölhisar, Ağlasun, Çeltikçi, Bucak ve Yeşilova ilçelerinde uygun alanlar olduğunu belirlemişlerdir. Oral (2020) Karabük ilinde güneș enerjisi uygulamalarının firsatlar ve riskler bağlamında analizini gerçekleştirdiği çalışmasında Karabük ili için çatı ve yan yüzey GES uygulamalarının yerel ölçekte rasyonel seçenek olduğunu sonucuna varmiştır.

Ülkemiz coğrafi konum olarak $36-42^{\circ}$ kuzey enlemleri ile $26-45^{\circ}$ doğu boylamları arasında yer alması nedeniyle güneş enerjisi potansiyeli bakımından dünya üzerinde pek çok ülkeye göre daha avantajlı durumdadır (Çiftci ve Altundağ 2017). Güneș enerjisinden elektrik üretimi çalışmalarında potansiyel belirlemek ve güneş enerjisini etkin kullanabilmek amaçlarıyla Enerji İşleri Genel Müdürlüğü tarafindan Türkiye Güneş Enerjisi Potansiyeli Atlası (GEPA) hazırlanmıştır. GEPA dikkate alındığında Türkiye'nin yıllık toplam güneşlenme süresinin 2.741 saat, günlük toplamının ise 7,5 saat, yıllık toplam gelen güneş enerjisinin $1.527 \mathrm{kWh} / \mathrm{m}^{2}$-yıl, günlük toplamının ise 4,18 kWh $/ \mathrm{m}^{2}$-gün değerinde olduğu görülmektedir. Ayrıca bölgesel güneş enerjisi parametre değerleri incelendiğinde, ülkemizde hemen hemen her noktada güneş enerjisinden direk veya dolaylı yararlanma olanağı bulunmaktadır (ETKB, 2020).

Çalışma alanı olan Karabük İl merkezinin yıllık toplam güneş radyasyonu 1400-1500 KWh/m²-yl arasındadır. Ayrıca Karabük'ün aylık ortalama günlük güneşlenme süresi yaklaşık 6,5 saat, yılık ortalama toplam güneşlenme süresinin ise yaklaşık 2.373 saattir. Karabük'ün global radyasyon değerlerinin ise haziran ve temmuz aylarında en yüksek olduğu, aylık ortalama günlük ışınım şiddetinin yaklaşık $3,7 \mathrm{kWh} / \mathrm{m}^{2}$, yıllık ortalama toplam global radyasyon değerinin ise yaklaşık $1.351 \mathrm{kWh} / \mathrm{m}^{2}$ olduğu görülmektedir (EIGM, 2020).

Karabük il merkezinde Karabük'ün 5. büyük enerji santrali olan ve 3.619 konutun enerji ihtiyacını karşılayabilecek miktarda elektrik üreten, 7 MWe kurulu gücünde Enerjisa Karabük Güneş Enerji Santrali ve Safranbolu ilçesinde 0,67 MWe kurulu gücünde Tema Trend Gayrimenkul Güneș Enerjisi Santrali (Enerji Atlası, 2020) ile 0,022 MWe kurulu gücünde Karabük Üniversitesi Güneş Enerjisi Santrali bulunmaktadır (Şevik, 2017). Karabük ilindeki mevcut elektrik santrallerinin kaynaklarına göre kurulu gücün dağılımı incelendiğinde hidroelektrik santrali (HES) ve kömür ağırlıklı elektrik üretimi olduğu görülmektedir (Şevik, 2017). İl genelinde toplam kurulu gücü içinde termik ve hidroelektrik santrallerin toplam payı \%92 düzeyinde iken GES'lerin payı \%8 düzeyindedir (Oral, 2020). Bu çalışma ile GEPA (Türkiye Güneş Enerjisi Potansiyeli Atlası) dikkate alınarak Karabük İlinde mevcut HES'lere ek olarak yine yenilenebilir enerji kaynaklarından biri olan güneş enerjisinden yararlanılabilmesi için Karabük il merkezi örneğinde uygun GES alanların belirlenmesi amaçlanmıştır. Bu amaçla Karabük ilinde potansiyel GES kurulumu için uygun yer seçimi, çoklu seçim 
kriterlerinin yönetilmesinde faydalı çözüm üreten bir sistemden meydana gelmesi sebebiyle CBS tabanlı çok kriterli karar verme analizi yöntemi ile olușturulmuştur. Bu bağlamda veri katmanları olarak; güneş radyasyonu, eğim, bakı, yola olan uzaklık, akarsuya olan uzaklık, fay hatlarına uzaklık, litoloji, arazi kullanımı, yerleşim alanlarına olan uzaklık ve trafoya olan uzaklık faktörleri kullanılmıştır. Çalışmada kullanılan tüm faktörler CBS yazılımı kullanılarak raster yapıda üretilmiș ve ikili karşılaştırma matrisi ile her bir faktörün ağırlık değerleri belirlenmiştir. Bu aşamadan sonra birleştirme analizi ile sınıflandırılmış ölçüt haritaları birleştirilerek GES için en uygun alanları gösteren uygunluk sonuç haritası elde edilmiştir. Karabük'te mevcut bulunan güneş enerji santrallerinin artması ile en azından konutların enerji ihtiyacının yenilenebilir enerji kaynaklarından biri olan güneş enerjisinden sağlanması Karabük'te sağlıklı çevre, temiz ve ucuz enerji temini açısından önem sunmaktadır.

\section{GEREÇ VE YÖNTEM}

\section{1. Çalıșma Alanı}

Çalışma alanı $40^{\circ} 57^{\prime}$ ve $41^{\circ} 34^{\prime}$ kuzey enlemleri ile $32^{\circ} 04^{\prime}$ ve $33^{\circ} 06^{\prime}$ doğu boylamları arasında ve Batı Karadeniz bölgesinde bulunan Karabük ilinin şehir merkezinde yer almakta olup 12.636 ha alan kaplamaktadır (Şekil 1). Karabük ilinin kuzeyinde Bartın, batısında Zonguldak, güneybatısında Bolu, güneydoğusunda Çankırl, kuzeydoğu ve doğusunda ise Kastamonu illeri yer almaktadır. Engebeli bir topoğrafyaya sahip olan Karabük'ün yaklaşık olarak \%65'i ormanlarla kaplı olup başlıca akarsuları Filyos çayı, Filyos çayının kolları olan Araç ve Soğanlı çayları ile Eskipazar çayıdır (Karabük Belediyesi, 2020). İlde Demir-Çelik ve buna bağlı sektörler gelișmiștir (Karabük Valiliği, 2020).

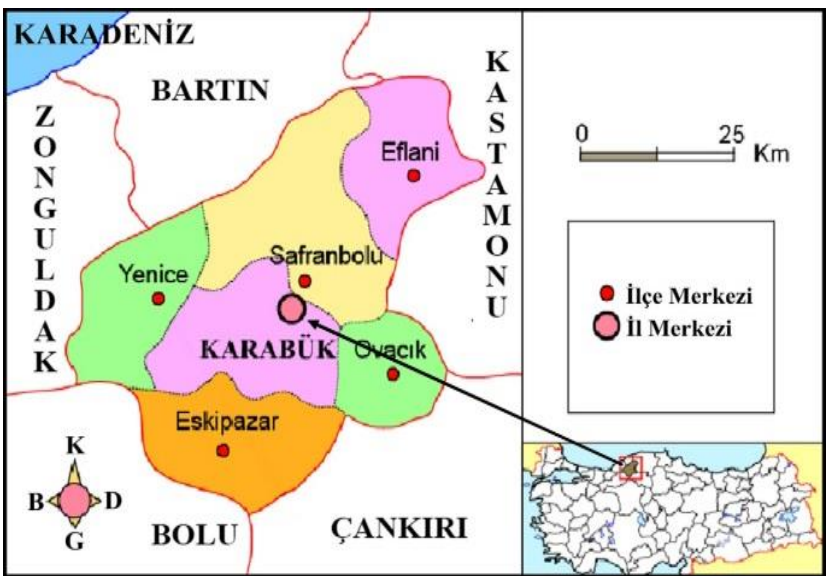

Şekil 1. Çalışma alanı yer bulduru haritası (URL-1 2020)

Karabük Kardemir Termik santralinde kullanılan kömür miktarı yıllık 122.861 ton uçucu kül miktarı ise yine yllık 17.704,27 ton olarak gerçekleşmiştir (Karabük ÇŞIM, 2019). Karabük, Karadeniz Bölgesinin yağışlı ve İç Anadolu Bölgesinin kurak iklimi arasında kalan bir alanda yer almaktadır ve ılıman iklim özelliği göstermektedir. Karabük İlinde yıllık ortalama sıcaklık $13^{\circ} \mathrm{C}$ olup yazlar serin, kışlar ılık geçmektedir (Karabük Meteoroloji Müdürlüğü, 2005). Karabük İlinin nüfusu
248.458, merkez ilçesinin nüfusu ise 133.615 kişidir (TUİK, 2020).

\subsection{Kullanılan Parametreler}

GES yer seçimi için yapılan çalışmalarda en üst düzeyde sonuç sağlanabilmesi ve doğru bir analiz yapılabilmesi için en temel ihtiyaç olan verilerin uygun bir şekilde temin edilmesi gerekmektedir (Memişoğlu, 2014). Yapılan literatür araştırması sonucunda yaygın kullanılan ve çalışma alanı için uygun olan katmanlar seçilmiştir (Asakereh ve ark., 2017; Uyan, 2013; Noorollahi ve ark., 2016; Al Garni ve Awasthi, 2017). Bu çalışmada güneş radyasyonu, eğim, bakı, yola olan uzaklık, akarsuya olan uzaklık, fay hatlarına uzaklık, litoloji, arazi kullanımı, yerleşim alanlarına olan uzaklık ve trafoya olan uzaklık faktörleri kullanılarak uygun GES kurulabilecek sahalar tespit edilmiştir. Karabük ili göçmen kuş rotası üzerinde olmadığından (Tarım ve Orman Bakanlığı 2020) analizde göç yollarına olan uzaklık parametresi kullanılmamıştır.

\subsubsection{Güneş radyasyonu}

Güneş radyasyonu, kurulacak santralden elde edilecek enerjiyi doğrudan etkilediği için en önemli kriterlerden biridir. $\mathrm{Bu}$ kriter birçok çalışmada irdelenmiştir (Charabi ve Gastli, 2011; Effat, 2013; Kengpol ve ark., 2013; Sánchez-Lozano ve ark., 2013; Uyan, 2013). Çalışmada kullanılan güneş radyasyonu haritası Şekil 2a'da verilmiştir.

\subsubsection{Trafo merkezlerine olan uzaklık}

GES'lerin yerlerinin belirlenmesinde Trafo merkezlerine olan uzaklık ekonomik yönden önemli bir faktördür. Tesis kurulumunda trafo merkezine yakınlık maliyet açısından avantaj sağlamaktadır (Yalçın ve Yüce, 2020). Yer seçiminde trafo merkezlerine olan uzaklığın $10 \mathrm{~km}$ 'den fazla olması istenilen bir durum değildir (Uyan, 2017). Çalışma alanın da trafo merkezine olan uzaklık faktörü 7 sınıf altında değerlendirilmiştir (Şekil 2b)

\subsubsection{Eğim}

GES'lerin yerlerinin belirlenmesinde önemli faktörlerden birisi de eğim kriteridir. GES panellerinin kurulacağı yerlerin eğiminin düşük olması istenmektedir. GES kurulumunda eğimin çok olması, istenmeyen bir durumdur. Fazla eğim güneş panellerinin birbirine gölge yapmasına neden olacağından dolayı panellerin yerleștirileceği yerlerin eğimin az olması gerekmektedir. Ayrıca güneşlenme açısından, eğimlerin güney yönünde olması da arazinin önemini arttıran önemli bir unsurdur (Effat, 2013; Noorollahi ve ark., 2016). GES uygun yerler için arazi eğiminin \%3'ten küçük olması istenmektedir (Hang ve ark., 2008). Çalışma alanına ait eğim verisi bölgeye ait sayısal yükseklik modelinden üretilmiştir. Üretilen eğim haritası 1 dereceden küçük, 1-2 derece, 2-3 derece, 3-4 derece ve 4 dereceden büyük olmak üzere 5 sınıfa ayrılmıştır (Şekil 2c). 


\subsubsection{Arazi kullanımı}

Arazi kullanımı GES'lerin yerlerinin belirlenmesinde çevresel bir faktör olarak kabul edilir (Uyan 2013). GES kurulması bölgedeki doğal yaşamı etkileyeceği için koruma alanlarından da belirli bir mesafe uzaklıkta olması gereklidir (Uzar ve Koca, 2020). Bu çalışmada arazi kullanımı kaya, mera, orman, bahçe tarım alanı, tarım alanı ve yerleşim olmak üzere 6 sınıfta incelenmiştir (Çağlayan, 2019). Çalışma alanına ait arazi kullanım haritası Şekil 2d'de gösterilmiştir.

\subsubsection{Yollara olan uzaklık}

GES uygun yer seçiminde yollara (kara ve demir) olan uzaklık santralin bakım ve onarım masrafları açısından önemli bir kriterdir. Tesisin ilk kurulumunda yollara yakın olması yapılacak alt yapı çalışmalarında maliyetin düşük olmasını sağlar ve ayrıca ulaşım amaçlı yeni yollarının açılması sırasında çevre arazilerin zarar görmesiyle sonuçlanabilecek olası zararları engeller (Uyan, 2017; Eroğlu, 2018). Ama yollardan geçen trafiğin bıraktı̆̆ı atıklar güneş panellerini olumsuz etkileyeceğinden ve güvenlik açısından önemli sıkıntılar doğurabileceğinden dolayı literatürde, GES'lerin yollara 100 m'den yakın olmaması kabul görmüștür (Uzar ve Koca, 2020). Çalışma alanın da yol hatlarına uzaklık faktörü 8 sınıf altında değerlendirilmiştir (Şekil 2e).

\subsubsection{Akarsuya olan uzaklık}

Akarsuya olan uzaklık GES’nin taşkınlardan etkilenmemesi için dikkate alınması gereken bir faktördür. $\mathrm{Bu}$ nedenle literatürde GES'ler in akarsulardan en az 400m uzaklıkta olması kabul görmüştür (Uzar ve Koca, 2020). Çalıșma alanın da akarsuya olan uzaklık faktörü 7sınıf altında değerlendirilmiştir (Şekil 2f).

\subsubsection{Jeoloji}

Karar verme sürecinde kullanılan parametreler, en uygun alternatifleri belirleyebilmek için kullanılan ve alanı karakterize eden değerler olmakla birlikte uygulanmış projelerden elde edilen tecrübelere dayanılarak bazı önemli parametreler de kullanılmaktadır. Bu parametrelerden biri de arazinin jeolojik yapısıdır (Uyan, 2017). Santralin kurulacağı alanın jeolojik yapısı proje maliyetini doğrudan etkilemektedir (Eroğlu, 2018). Ayrıca zeminin çakmalı montaj sistemlerine uygun olması gerekmektedir.

Çalışma alanında yüzeyleme gösteren 5 farklı litolojik formasyon ve bu formasyonlara ait 3 üye bulunmaktadır. Çalışma alanında yaşlıdan gence doğru sirasiyla Ulus formasyonu $(\mathrm{Ku})$ ve bu formasyonun Sunduk (Kus) ve Ahmetusta (Kua) üyeleri, Safranbolu formasyonu (Tes), Karabük formasyonu (Teka) ve bu formasyonun Çerçen üyesi (Tekaç), Örencik formasyonu (Tplö) ve alüvyon (Qal) yer almaktadır. Şeyl, kiltaşı, marn, kireçtaşı, kumtaşı, kumlu kireçtaşı ve çakıltaşı ardalanmasından oluşan Ulus formasyonu (Ku), Ahmetusta (Kua) ve Sunduk (Kus) olmak üzere 2 üyeye ayrılmaktadır. Ulus formasyonu içindeki çakıltaşları Ahmetusta üyesini (Kua) oluşturmakta olup gri, sarı, kahverengimsi sarı renklerde, orta-kalın katmanlı ve masif görünümlüdür. Sunduk üyesi (Kus) ise gri, bej renkli, orta-kalın katmanlı kireçtaşlarından oluşmakta ve kalınlığı yaklaşık olarak 2000 metreye ulaşmaktadır. Safranbolu formasyonu (Tes) altta ince çakıltaşıkumtaşı seviyesi ile başlayıp üste doğru karbonatlı kumtaşı, kumlu kireçtaşı ve kireçtaşı seviyesine geçmektedir. Sarımsı beyaz, açık gri ve pembe renklerde ve orta-kalın tabakalı olan Safranbolu formasyonunun kalınlığı 50-500 metre arasında değişmektedir. Gri-haki yeşil renkli ve orta-kalın katmanlı özellik sunan Karabük formasyonu (Teka) alt seviyelerinde marn, üste doğru kiltaşı ve kumtaşı aradalanmasından oluşur. Formasyonun üst kesimlerinde ince kömür seviyeleri de bulunmaktadır. Karabük formasyonunun üyesi olan Çerçen Üyesi (Tekaç) ise kırmızı, yeşil renkli çakıltaşı, kumtaşı, silttaşı, kiltaşı ve çamurtaşı ardalanmasından oluşmaktadır. Çalışma alanının genç çökelleri olan ortakalın katmanlı Örencik formasyonu (Tplö) kırmızı, sarımsı kırmızı ve kahrengi karasal çakıltaşı, kumtaşı ve çamurtaşı ardalanmasından oluşur. Çalışma alanının en genç birimi Kuvaterner yaşlı alüvyon (Qal) olup akarsu yatakları, eski çukurluklar ve düz alanlar üzerinde gelişen çakıl, kum ve çamur çökellerinden oluşmaktadır (Timur ve Aksay, 2002). Alüvyon, tutturulmamış ve ayrık taneli birim özelliği sunmasından dolayı GES kurulumu uygun olmayıp, çalışma alanındaki diğer jeolojik formasyonlar GES kurulumu için uygundur. Çalışma alanına ait jeoloji haritası Şekil 2g'de verilmiştir.

\subsubsection{Fay hatlarına olan uzaklık}

GES kurulumu için yer seçiminde deprem riski az olan bölgeler seçilmelidir. Karabük civarında, bölgedeki KB-GD yönlü sıkışmaya bağlı olarak kuzey bloğu yükselmiş, güney bloğu düşmüş KD-GB doğrultulu düşey atımlı fay yer almaktadır (Timur ve Aksay, 2002). Fay hattı verisi MTA Genel Müdürlüğü'nün sitesinden sunulmuş olan Fay Haritasından sayısallaştırılarak elde edilmiştir (MTA, 2020) ve analizlerde kullanılmak üzere $1000 \mathrm{~m}$ aralıklarla beş farklı buffer alanı oluşturulmuştur (Şekil 2h).

\subsubsection{Yerleşim Alanlarına olan uzaklık}

Yerleşim alanlarına olan uzaklık GES yer seçimi için dikkate alınması gereken faktörlerden biridir. Çünkü yerleşim yerleri her geçen gün büyümektedir ve uzun vadede düşünüldügünnde ise GES'lerin bu bölgeler içinde kalma ihtimalleri olduğundan Güneş santrallerini yerleşim yerlerine çok yakın olmaması gerekmektedir (Uzar ve Koca, 2020). Ama GES'lerin yerleşim yerlerinden çok uzakta olması da bölgenin enerji iletim masraflarını arttıracaktır. Bu nedenle GES'lerin yerleșim yerine ideal bir uzaklıkta olması istenmektedir (Eroğlu, 2018). Çalışma alanında yerleşim alanlarına uzaklık faktörü 7 sınıf altında değerlendirilmiştir (Şekil 2i).

\subsubsection{Bakı}

GES kurulumu için bakı ülkemizin yüksek ve engebeli olmasından dolayı önemli bir faktördür. GES yer seçimi için gün içerisinde güneşten en fazla fayda 
sağlanacağ güney cephelerinin belirlenmesi gerekmektedir (Gerçek, 2018; Yalçın ve Yüce, 2020). Çalıșma alanına ait bakı haritası -1 ile 360 derece aralığında olmak üzere, toplam 10 sınıfı içerecek şekilde değerlendirmeye alınmıştır (Şekil 2j).

\subsection{Yöntem}

$\mathrm{Bu}$ çalıșmada duyarlılık haritasının üretilmesi için CBS tabanlı çok kriterli karar verme analizi (CBS-ÇKKA) yöntemi, ÇKKA çözümünde ise Analitik Hiyerarşi (AHY) ve AHY ile uyumlu olarak geliştirilen Ağırlıklandırılmış Doğrusal Birleştirme (ADB) yöntemleri kullanılmıştır. ÇKKA, karar problemlerinin çözümünde bir dizi alternatif çözümlemesi ile uyuşumsuz verilerden ve bu verilere sahip zıt kriterlerden yararlanılması işlemidir (Malczewski, 1999). AHY ise karar vericinin tüm alternatiflerini tüm kriterler ile beraber değerlendirerek, birbirlerinin göreceli önemlerine göre ikili karşılaştırmalar yapması prensibine dayanmaktadır (Saral ve Musaoğlu, 2011). AHY'nin karar vericiler tarafından tercih edilmesinin nedeni, çok kriterli kararlarda sübjektif kriterleri dikkate alması, kullanımı kolay ve anlaşılır bir yöntem olmasıdır (Ömürbek ve ark., 2013; Soba ve Bildik, 2013). Çok kriterli karar verme problemlerinde karşılaşılan temel sorun, çeşitli alternatifler arasından birden çok kriter göz önünde bulundurarak seçim yapabilmek için ağırlık, önem veya üstünlük belirlemektir. İşte bu sorunu çözmede AHY etkin olarak kullanılan bir ÇKKA yöntemidir. AHY yönteminin en önemli özelliklerinden biri karar vericinin hem objektif hem de sübjektif düşüncelerini karar sürecine dâhil edebilmesidir (Kuruüzüm ve Atsan, 2001). Bu nedenle de AHY karar almada, grup ve bireyin önceliklerini de dikkate alan, nitel ve nicel değişkenleri bir arada değerlendiren matematiksel bir yöntemdir. $\mathrm{Bu}$ durum da AHY'yi diğer karar verme yöntemlerine göre daha güçlü kılmaktadır (Gülenç ve Aydın Bilgin, 2010).

AHY amacı belirlenen ölçütlere göre en uygun seçeneğin belirlenmesidir (Kurşunoğlu ve Önder, 2014). AHY karșllaștırmalı karar verme ve tercih matrisinin belirlenmesi ile bașlamaktadır. İkili karşılaștırmanın yapılabilmesi için, Saaty (1977 ve 2008) tarafından önerilen AHY Değerlendirme Ölçeğinden (Tablo 1) yararlanılarak ikili karşılaştırma matrisi oluşturulur. İkili karşılaştırma matrisi oluştururken kriter çiftlerinden hangisinin daha önemli olduğu ve önemli olan kriterin diğer kritere göre önem derecesi ne kadar olmalı sorularına cevap verilmesi gerekir.

Karşılaștırma matrisinin olușturulmasından sonraki aşama ise kriterlerin ağırlıklarının hesaplanmasıdır. Oluşturulan karşılaştırma matrisi ile her bir kriterin ağırlığı hesaplanarak Tablo 2'de verilmiştir. Karşlaştırma matrisi sonucu elde edilen en yüksek ağırlığa sahip faktörler sırasıyla güneş radyasyonu, trafoya olan uzaklık, eğim, bakı, arazi kullanımı, yola olan uzaklık, akarsuya olan uzaklık, Jeoloji, fay hattına olan uzaklık ve yerleșim alanlarına olan uzaklık olarak belirlenmiștir.

AHY kendi içinde tutarlı bir sistematiğe sahip olmasına rağmen sonuçlar karar vericinin kriterler arasında yaptığı bire bir karşılaştırmadaki tutarlılığa bağlı olacağından kriterlerin ağırlık hesabından sonra rastgele oluşturulan matris derecelendirmesindeki olabilirliği anlamına gelen Tutarlılık oranının (CR) hesaplanması gerekmektedir (Mutlu ve Sarı, 2017). Saaty (2000) maksimum tutarlılık oranını \%10 olarak önermektedir. Bu değerin üzerinde bir değer bulunursa ikili karşılaştırma matrisinin tekrardan oluşturulması gerekmektedir (Drobne ve Lisec, 2009). Tutarlılık oranı rastgele indeks değeri (RI) ve tutarlılık ayırma ölçütü sağlayan tutarlılık indeks değeri (CI)'ne bağlı olarak

$C R=\frac{C I}{R I}$ şeklinde hesaplanır.

CI değeri ise $\lambda$ tutarlılık vektör ortalaması ve $n$ kriter sayısına bağlı olarak

$C I=\frac{(\lambda-\mathrm{n})}{(n-1)}$ şeklinde elde edilir.

Tablo 1. AHY değerlendirme ölçeği (Saaty, 1977; Saaty, 2008).

\begin{tabular}{ll}
\hline Önem Derecesi & Tanımlama \\
\hline 1 & Eşit derece önemli \\
3 & 1. ölçüt 2.'ye göre biraz daha önemli \\
5 & 1. ölçüt 2.'ye göre fazla önemli \\
7 & $\begin{array}{l}\text { 1. ölçüt 2.'ye göre çok fazla önemli } \\
\text { 1. ölçüt 2.'ye göre olası en kuvvetli } \\
\text { öneme sahip veya tercih ediliyor. } \\
\text { Ara değerler, uzlaşma gereken } \\
\text { durumlarda kullanılmaktadır. }\end{array}$ \\
\hline
\end{tabular}

Tablo 2. Karşılaştırma matrisi ve ağırlık değerleri (a Güneş radyasyonu, b Trafoya uzaklık, c eğim, d Arazi kullanımı, e Yola olan uzaklık, f Akarsuya olan uzaklık, g Jeoloji, h Fay hattına olan uzaklık, i Yerleşim alanlarına olan uzaklık, j Bakı)

\begin{tabular}{lccccccccccc} 
& $\mathrm{a}$ & $\mathrm{b}$ & $\mathrm{c}$ & $\mathrm{d}$ & $\mathrm{e}$ & $\mathrm{f}$ & $\mathrm{g}$ & $\mathrm{h}$ & $\mathrm{i}$ & $\mathrm{J}$ & Ağırlı (\%) \\
\cline { 2 - 10 } $\mathrm{a}$ & 1 & 3 & 2 & 8 & 6 & 7 & 7 & 8 & 7 & 3 & 0,28 \\
$\mathrm{~b}$ & & 1 & 3 & 4 & 5 & 6 & 6 & 7 & 6 & 2 & 0,20 \\
$\mathrm{c}$ & & & 1 & 2 & 4 & 5 & 5 & 6 & 5 & 3 & 0,15 \\
$\mathrm{~d}$ & & & & 1 & 3 & 4 & 4 & 5 & 4 & $1 / 4$ & 0,08 \\
$\mathrm{e}$ & & & & & 1 & 3 & 2 & 3 & 4 & $1 / 6$ & 0,05 \\
$\mathrm{f}$ & & & & & & 1 & 3 & 2 & 2 & $1 / 3$ & 0,04 \\
$\mathrm{~g}$ & & & & & & & 1 & 2 & 2 & $1 / 4$ & 0,03 \\
$\mathrm{~h}$ & & & & & & & & 1 & 3 & $1 / 5$ & 0,03 \\
$\mathrm{i}$ & & & & & & & & 1 & $1 / 4$ & 0,02 \\
$\mathrm{j}$ & & & & & & & & & 1 & 0,12 \\
\hline
\end{tabular}

Oluşturulan karşılaştırma matrisindeki değerlerin ve elde edilen ağırlıkların tutarlı olup olmadıklarının belirlenmesi amacıyla hesaplanan "Tutarlılık oranı" (CR) değeri ise 0,08 olarak hesaplanmiştır. Elde edilen oran Saaty (2000) tarafından önerilen 0,10'un altında olduğu için ikili karşılaştırma matrisi sonucu bulunan değerlerin birbirleriyle tutarlı oldukları kanaatine varılmıştır.

Kriterlerin ağırlıklarının ve tutarlılık oranının hesaplanmasından sonraki aşama ise ADB yöntemi ile faktörlerin birbirleriyle birleştirilmesi ve sonuç haritanın elde edilmesidir. 

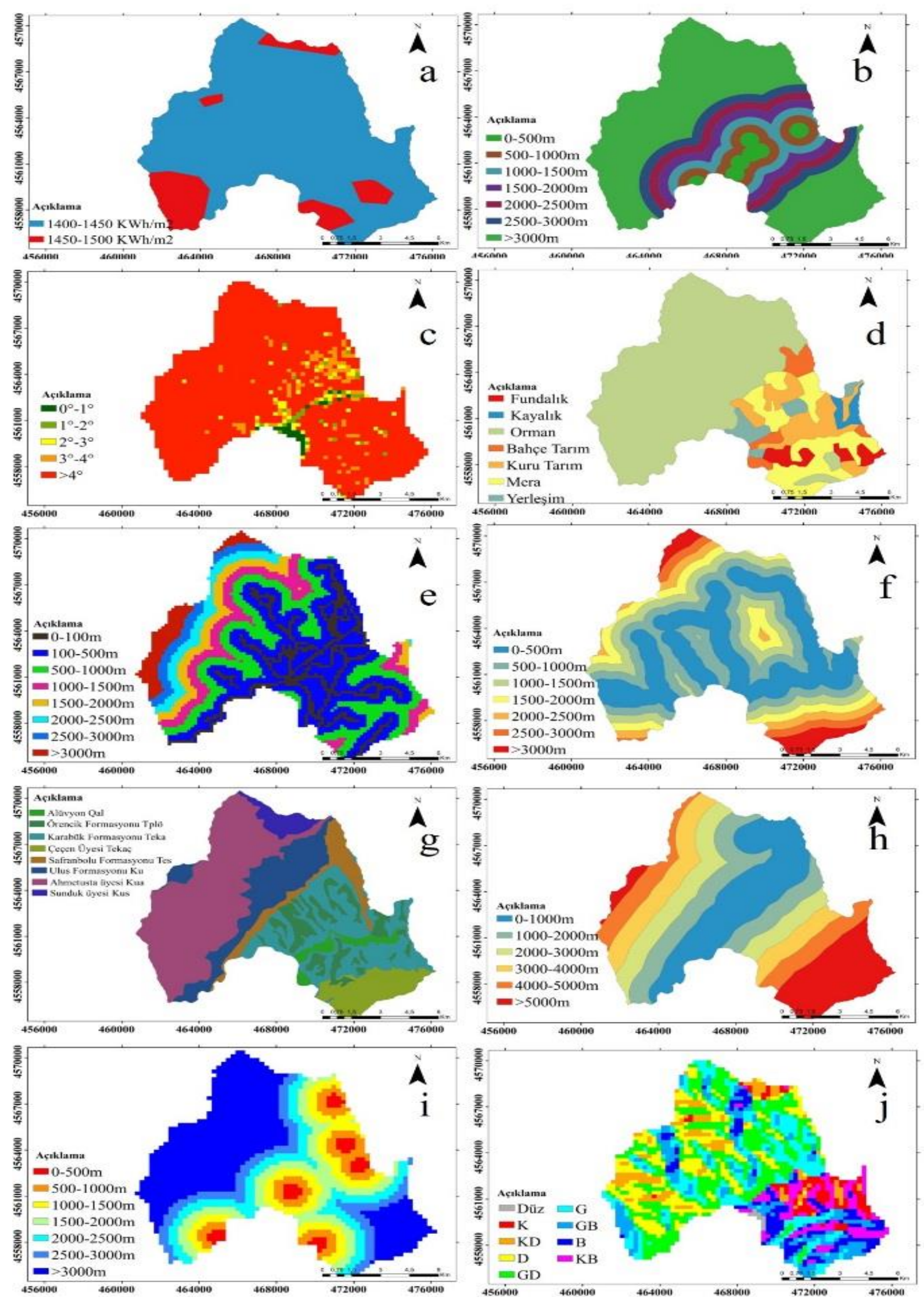

Şekil 2. Kullanılan parametreler. a güneş radyasyonu, b trafoya uzaklık, c eğim, d arazi kullanımı, e yola olan uzaklık, f akarsuya olan uzaklık, g jeoloji, h fay hattına olan uzaklık, i yerleşim alanlarına olan uzaklık, j bakı 


\section{BULGULAR VE TARTIŞMA}

GES yer seçimi için CBS tabanlı ÇKKA yöntemlerinin kullanılması pek çok alternatifin sürece dahil edilmesine ve bunun sonucu olarak da farklı stratejiler geliştirilmesine olanak sağlamaktadır. Bununla birlikte, analiz sonucunu etkileyen en önemli unsur, analizi yapılan konuya etki eden faktörlerin en uygun şekilde tespit edilmesidir. Analiz sonucu üretilen haritaların sağlıklı değerlendirilebilmesi de tespit edilen faktörlerin uygunluğuyla doğru orantılıdır (Uyan, 2017).

$\mathrm{Bu}$ çalışmada CBS dayalı ÇKKA yöntemi ile Karabük iline ait 10 kriterin normalleştirilmesi, kriterlerin ağırlıklarının belirlenmesi ve tüm kriterlerin toplanması ile GES yapım yeri için duyarlılık sınıfları haritası üretilmiștir. Üretilen duyarlılık haritası yüksek, orta, düşük ve çok düşük duyarlı olmak üzere dört farklı sınıfa ayrılmıştır. Gerçekleştirilen analizler sonucunda yüksek duyarlılık $\% 0,37$, orta duyarlılık $\% 24,16$, düşük duyarlılık \%75,36 ve çok düşük duyarlılık \%0,11 oranında elde edilmiştir (Şekil 3). Elde edilen sonuçlara göre, çalışma alanında GES kurulumu için yüksek duyarlılığa sahip oldukça uygun alanların 47,38 ha, orta duyarlılığa sahip uygun alanların ise $3.052,51$ ha alan kapsadığı görülmüştür. Karabük İlinde GES kurulumuna uygun olan yüksek ve orta duyarlılığa sahip olan toplam 3.099,89 ha'llk bu alan çalışma alanının güneyinde ve doğusunda yer almakta ve tüm alanın \%24,53'ünü kapsamaktadır. Çalışma alanının kuzeyi ve batısını kapsayan \%75,47'lik kısmı ise GES kurulması için uygun değildir.

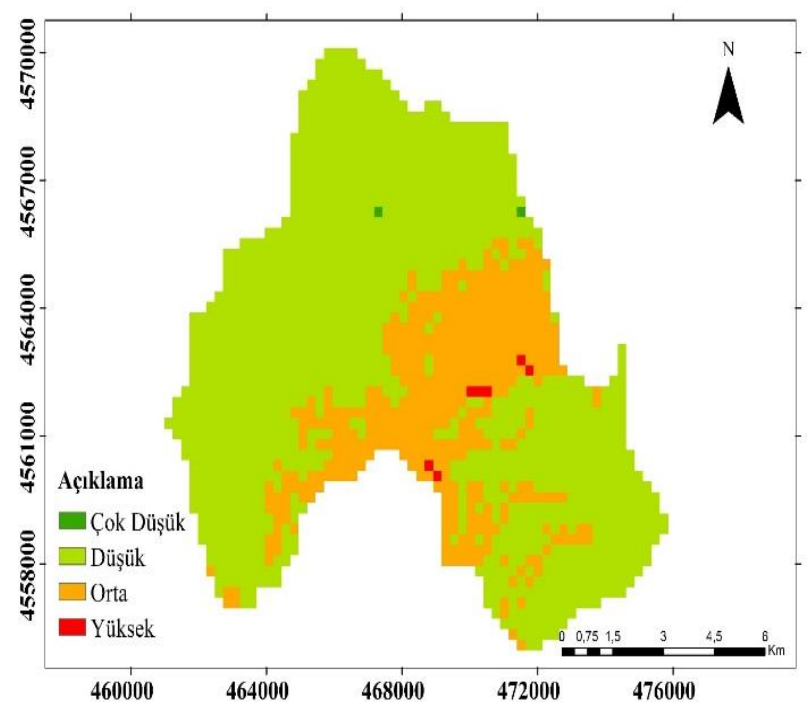

Şekil 3. Uygun GES yapım yeri alanı için duyarlılık sinıfları haritası

\section{SONUÇLAR}

Türkiye ölçeğinde hazırlanmış bir harita olan GEPA Güneş Enerjisi Potansiyel Atlası GES kurulumuna uygun yerlerin belirlenmesinde genel bir fikir vermesiyle birlikte tek başına yeterli değildir. Bu nedenle GES yer seçimi konusunda birçok değișken etkili olmaktadır (Effat, 2013). 10 faktöre dayalı olarak CBS tabanlı ÇKKA-AHY yöntemi ile yapılan bu çalışma sonucunda, çalışma alanının GES yapım yeri için ağırlıklı olarak orta ve düşük duyarlılık düzeyinde olduğu tespit edilmiştir. Enerji Genel Müdürlüğünün GEPA atlasında çalışma alanının güneș radyasyonu değerleri ile bu çalışmada belirlenen bulguların birbiriyle örtüştüğü görülmektedir. Bu durum, bu çalışmada kullanılan kriterlerin genel düzeyde değerlendirmeler için yeterli olduğunu göstermektedir. HES ve kömüre dayalı elektrik üretiminin ağırlıklı olduğu Karabük İlinde yenilenebilir ve temiz bir enerji türü olan güneș enerjisinden faydalanılabilmesi amacıyla en azından başlangıç için yüksek ve orta duyarlılık özelliği sunan yerlere GES kurulması hem çalıșma alanında temiz ve sağlıklı bir çevre ve ucuz enerji temini hem de ülke ekonomisine katkı sağlayacaktır. Ayrıca, bu çalışmanın literatürde yer almasiyla, GES kurulum yeri belirleme çalışmalarında daha geniş sayıda kriterlerin kullanılmasına katkı sağlaması hedeflenmektedir. GES kurulum aşaması için sonraki yapılacak çalışmalarda kurulması planlanan GES'in modeli, boyutu ve doğal çevre ile ilişkisinin ayrıntılı değerlendirilmesi gerekmektedir. Ayrıca GES kurulumu için uygun olarak belirlenen alanlarda GES'lerin yerleștirileceği parsellerin mülkiyet durumları da dikkate alınmalıdır. Gerçekleştirilen bu çalışma ile CBS tabanlı ÇKKA ve AHY yöntemlerinin yer uygunluk haritalarının üretilmesinde oldukça güçlü bir yöntem olduğu da vurgulanmaktadır.

\section{ARAŞTIRMACILARIN KATKI ORANI}

Deniz Arca: Literatür tarama, Araştırma, Veri toplama, Analiz, Veri ve bulgu yorumlama, Makale yazma; Hülya Keskin Çıtıroğlu: Literatür tarama, Araştırma, Veri toplama, Veri ve bulgu yorumlama, Makale yazma, Düzenleme ve kontrol

\section{ÇATIŞMA BEYANI}

Herhangi bir çıkar çatışması bulunmamaktadır.

\section{KAYNAKÇA}

Al Garni H Z \& Awasthi A (2017). Solar PV power plant site selection using a GIS-AHP based approach with application in Saudi Arabia. Applied Energy, 206, 1225-1240.

Alternatürk (2020). Güneş enerjisinin kullanım alanlarl. https://www.alternaturk.org/gunesenerjisi-kullanim-alanlari.php Erişim tarihi:16.06.2020.

Asakereh A, Soleymani M \& Sheikhdavoodi M J (2017). A GIS-based Fuzzy-AHP method for the evaluation of solar farms locations: Case study in 
Khuzestan province, Iran. Solar Energy, 155, 342-353.

Can E (2019). Analysis of risks that are based on the aerial photography used in photogrammetric monitoring maps for environmental wind power energy plant projects. Environmental Monitoring and Assessment, 191, 746.

Can E \& Erbıyık H (2020). Rüzgâr enerji santrali projelerinde topografik yersel ölçme ve gözlemlerden kaynaklanan risklerinin incelenmesi. Afyon Kocatepe Üniversitesi Fen ve Mühendislik Bilimleri Dergisi, 20(4), 741-752.

Charabi Y \& Gastli A (2011). PV site suitability analysis using GIS based spatial fuzzy multicriteria evaluation. Renewable Energy, 36 (9), 2554-2561.

Çağlayan İ (2019). Karabük şehri ve çevresinde doğal ortam ile insan arasındaki ilişkiler. Yüksek Lisans Tezi. Van Yüzüncü Yıl Üniversitesi Sosyal Bilimler Enstitüsü Coğrafya ABD. Van.

Çağlayan N, Ertekin C \& Evrendilek F (2014). Spatial viability analysis of grid-connected photovoltaicpower systems for Turkey, Internatial Journal of Electrical Power and Energy Systems, 56,270278.

Çiftci A \& Altundağ E (2017). Burdur bölgesi güneş enerjisi potansiyelinin elektrik üretiminde kullanılabilirliği. Mesleki Bilimler Dergisi, MBD 6 (2), $111-120$.

Drobne S \& Lisec A (2009). Multi-attribute decision analysis in gis: weighted linear combination and ordered weighted averaging, Informatica (Slovenia), 33(4), 459-474.

Effat H A (2013). Selection of potential sites for solar energy farms in Ismailia Governorate, Egypt using SRTM and Multicriteria Analysis. International Journal of Advanced Remote Sensing and GIS 2(1),205-220.

EİGM (2020). Güneş enerjisi potansiyel atlası (GEPA)

http://www.yegm.gov.tr/MyCalculator/pages/7 8.aspx Erişim tarihi:17.06.2020.

Enerji Atlası (2020). Karabük güneş enerji santralleri, https://www.enerjiatlasi.com/gunes-enerjisiharitasi/karabuk Erişim tarihi:16.06.2020.

Eroğlu H (2018). Güneş enerji santralleri için uygunluk haritasının elde edilmesi: bir uygulama. Iğdır Üniversitesi Fen Bilimleri Enstitüsü Dergisi, 8(4), 97-106.

ETKB (2020). Bilgi merkezi, güneş, Enerji ve Tabii Kaynaklar Bakanlığı. https://enerji.gov.tr/bilgimerkezi-enerji-gunes, Erişim tarihi:17.10.2020.

Gerçek Y (2018). Güneş enerji santralleri için CBS ile en uygun yer tayini: Malatya ili örneği. Yüksek lisans tezi, Karadeniz Teknik Üniversitesi, Fen Bilimleri Enstitüsü, Trabzon.

Gülenç İ F \& Aydın B G (2010). Yatırım kararları için bir model önerisi: AHP yöntemi. Öneri Dergisi, 9 (34), 97-107.

Hang Q, Jun Z, Xiao Y \& Junkui C (2008). Prospect of concentrating solar power in China-the sustainable future. Renewable and Sustainable Energy Reviews 12,2505-2514.

Karabük Belediyesi (2020). Karabük. https://www.karabuk.bel.tr/default.asp\# Erişim tarihi:19.07.2020.

Karabük ÇŞİM (2019). Karabük ili 2018 yılı Çevre durum raporu. Çevre Şehircilik İl Müdürlüğü, Çed ve Çevre İzinleri Şube Müdürlüğü, Karabük. $161 \mathrm{~s}$.

Karabük Meteoroloji Müdürlüğü (2005). Karabük Meteoroloji İstasyonu Müdürlügü'nün ölçtüğü bazı değerler (Yayınlanmamış), Karabük.

Karabük Valiliği (2020). Karabük. http://www.karabuk.gov.tr/sehrimiz Erişim tarihi:19.07.2020.

Kengpol A, Rontlaong P \& Tuominen M (2013). A decision support system for selection of solar power plant locations by applying fuzzy AHP and TOPSIS: An empirical study. Journal of Software Engineering Application, 6 (9),470481.

Kurşunoğlu N \& Önder M (2014). Yeraltı maden işletmelerinde analitik hiyerarşi prosesi yöntemi ile uygun vantilatör seçimi. Türkiye 19. Kömür Kongresi, Zonguldak, 115-122.

Kuruüzüm A \& Atsan N (2001). Analitik hiyerarşi yöntemi ve işletmecilik alanındaki uygulamaları. Akdeniz İIBF Dergisi, 1(1), 83-105.

Malczewski J (1999). GIS and multicriteria decision analysis. John Wiley and Sons, Toronto, $408 \mathrm{~s}$.

Memişoğlu T (2014). Akarsu vadileri boyunca çevresel kirleticilerin coğrafi bilgi sistemleri ile analizi: Trabzon ili örneği. Yüksek Lisans Tezi, Karadeniz Teknik Üniversitesi, Fen Bilimleri Enstitüsü, Trabzon, 159s.

MTA (2020). Yerbilimleri harita görüntüleyicisi ve çizim editörü. Maden Tetkik Ve Arama Genel Müdürlüğü.

http://yerbilimleri.mta.gov.tr/anasayfa.aspx Erișim tarihi:10.08.2020.

Mutlu M \& Sarı M (2017). Çok kriterli karar verme yöntemleri ve madencilik sektöründe kullanımı. Bilimsel Madencilik Dergisi, 56(4), 181-196.

Noorollahi E, Fadai D, Akbarpour S M \& Ghodsipour S (2016). Land suitability analysis for solar farms exploitation using GIS and fuzzy analytic hierarchy process (FAHP) - a case study of Iran. Energies, 9(8), 643.

Oral M (2020). Solar energy potential of Turkey and evaluation of PV applications in local scale: Case of Karabük province. International Journal of Geography and Geography Education (IGGE), 42, 482-503.

Ömürbek N, Üstündağ S \& Helvacıoğlu Ö C (2013). Kuruluş yeri seçiminde Analitik Hiyerarşi Süreci (AHP) kullanımı: Isparta Bölgesi'nde bir uygulama. Yönetim Bilimleri Dergisi, 11(21),101-116.

REN21 (2019). Renewables 2019 global status report. Renewable Enerji Policy Network for the 21st century Paris, France, pp:336. https://www.ren21.net/wp- 
content/uploads/2019/05/gsr_2019_full_report _en.pdf Erişim tarihi:19.11.2019.

Saaty T L (1977). A scaling method for priorities in hierarchical structures. Journal of Mathematical psychology, 15, 231-281.

Saaty T L (2000). Fundamentals of decision making and priority theory. 2. Edition, RWS Publications, Pittsburgh.

Saaty T L (2008). The analytic hierarchy and analytic network measurement processes: Applications to decisions under risk. European Journal of Pure and Applied Mathematics, 1(1), 122-196.

Sánchez-Lozano J M, Teruel-Solano J, Soto-Elvira P \& García-Cascales M S (2013). Geographical information systems (GIS) and multi-criteria decision making (MCDM) methods for the evaluation of solar farms locations: Case study in south-eastern Spain. Renewable and Sustainable Energy Reviews 24,544-556.

Saral A \& Musaoğlu N (2011). Çok kriterli karar verme ve bilgi difüzyonu yöntemleri ile taşkın risk analizi. 13. Türkiye Harita Bilimsel ve Teknik Kurultayı, 18-22 Nisan, Ankara.

Soba M \& Bildik T (2013). İlçelerde fakülte yeri seçiminin analitik hiyerarşi süreci metodu İle belirlenmesi. Kafkas Üniversitesi İktisadi ve İdari Bilimler Fakültesi Dergisi, 4(5), 51-63.

Suh J \& Brownson J R S (2016). Solar farm suitability using geographic information system fuzzy sets and analytic hierarchy processes:Case study of Ulleung Island, Korea Energies 9, 648.

Şevik S (2017). İl bazında enerji dengesi analizi: Karabük örneği, Gazi Üniversitesi Fen Bilimleri Dergisi Part C: Tasarım ve Teknoloji, 5(4), 71-85.

Tarım ve Orman Bakanlığı (2020). Göç yolları. Tarım ve Orman Bakanlığı Koruma Kontrol Genel Müdürlüğü Hayvan Sağlık Daire Başkanlığı
http://www.kusgribi.gov.tr/TR/Genel/BelgeGos ter.aspx?F6E10F8892433CFFAAF6AA849816B2 EFA26CBFDF5F1B259F Erişim tarihi:21.06.2020.

TEİAŞ (2020). Türkiye elektrik üretim istatistikleri. https://www.teias.gov.tr/tr-TR/turkiyeelektrik-uretim-iletim-istatistikleri Erişim tarihi:10.05.2020.

Timur E \& Aksay A (2002). 1:100.000 ölçekli Türkiye jeoloji haritaları No:30 Zonguldak F-29 Paftası. MTA Jeoloji Etütleri Dairesi Ankara 23 s.

TUIKK (2020). Adrese dayalı kayıt sistemi sonuçları https://biruni.tuik.gov.tr/medas/?kn=95\&locale $=\operatorname{tr}$ Erişim tarihi:15.06.2020.

URL-1 (2020). Türkiye mülki idare haritaları http://cografyaharita.com/turkiye_mulki_idare_ haritalari.html Erişim tarihi: 06.09.2020.

Uyan M (2013). GIS-based solar farms site selection using analytic hierarchy process (AHP) in Karapinar region, Konya/Turkey. Renewable and Sustainable Energy Reviews 28,11-17.

Uyan M (2017). Güneş enerjisi santrali kurulabilecek alanların AHP yöntemi kullanılarak CBS destekli haritalanması. Pamukkale Üniversitesi Mühendislik Bilimleri Dergisi, 23(4), 343-351.

Uzar M \& Koca H (2020). Güneş enerjisi santrallerinin yer seçimi için uygunluk haritasının oluşturulmasında klasik ve bulanık mantığa dayalı yöntemlerin analizi: Menemen örneği. Jeodezi ve Jeoinformasyon Dergisi, $7(1), 11-28$.

Yalçın C \& Yüce M (2020). Burdur'da güneş enerjisi santrali (GES) yatırımına uygun alanların CBS tabanlı AHP yöntemiyle tespiti. Geomatik Dergisi $5(1), 36-46$. 